\title{
A Numerical Investigation of the Temperature Uniformity of a Billet due to Thermal Radiation in a Reheating Furnace
}

\author{
Tanawat Khoukit and Chittin Tangthieng* \\ Department of Mechanical Engineering, Faculty of Engineering, Chulalongkorn University, Phayathai \\ Rd.,Wangmai, Pahumwan, Bangkok 10330, Thailand \\ *E-mail: QED690@yahoo.com
}

\begin{abstract}
In Thailand, the iron and steel industry is one of the major industries to provide raw materials to other ones. In order to heat a billet to a proper temperature, it is fed into a reheating furnace, which generates heat by the combustion of fuel from direct-fired burners. After the temperature uniformity of the billet is achieved, it will be sent to the rolling process. The major mechanism of heat transfer in the reheating furnace is the thermal radiation because of the high combustion gas temperature. The temperature distribution of a billet subjected to the thermal radiation of the enclosure surfaces in a reheating furnace is presented in this study. The 2-D steady-state heat conduction equation is numerically solved by the finite volume method together with the Gauss-seidel iterative technique. A qualitative agreement between the numerical result and the data from filed measurement is presented. The variations of the temperature uniformity of the billet with different insulation thicknesses, flame temperatures and furnace floor temperatures are investigated. The result indicates the hot spot at the middle of billet originated from the position of combustion flame. When the wall insulation thickness is decreased, the thermal radiation of combustion flame is decreased, leading to the higher degree of the temperature uniformity of the billet. In case of the lower flame temperature or the higher the floor temperature, the degree of the temperature uniformity of the billet also increases.
\end{abstract}

Keywords: Temperature uniformity, reheating furnace, thermal radiation.

ENGINEERING JOURNAL Volume 20 Issue 1

Received 4 April 2015

Accepted 14 September 2015

Published 29 January 2016

Online at http://www.engj.org/

DOI:10.4186/ej.2016.20.1.35 


\section{Introduction}

The iron and steel industry is one of the most important industries to provide raw materials to the other one such as automotive, machinery, construction and electronic one. A continuous reheating furnace $[1,2]$ is the major process in the iron and steel industry. Sakamoto et al. [3] showed that the reheating furnace consumes substantially high amount of energy. The billet is heated to a proper temperature of 1,100$1,250^{\circ} \mathrm{C}$. The reheating furnace can be basically divided into three zones: preheating, heating and soaking zones. The combustion process from direct-fired burners is a heat source for the reheating furnace. The hot exhaust gas heats the billet in the preheating zone while the billet moves into reheating furnace. The billet is heated by the burners to a desired temperature in the heating zone whereas the soaking zone provides enough heat to achieve the desire of the billet temperature uniformity before been sent to the rolling process. The non-uniform temperature of the discharged billet may cause the damages to the final product.

To investigate the billet temperature uniformity, the experimental and numerical study has been conducted. Lindholm and Leden [4] studied a transient three dimension finite element method. The radiative heat transfer from gas, furnace wall and skid pipe cooled by water was modeled. The emissivity coefficient of furnace wall and billet was 0.9 and 0.8 respectively. The results show the effect of skid pipe on temperature distribution all of billet. The temperature of bottom surface is $1,223-1,260^{\circ} \mathrm{C}$. The temperature difference between top and bottom surface is approximately $36^{\circ} \mathrm{C}$. Kolenlo et al. [5] carried out an analysis of heat transfer model. The total heat transfer included the direct radiation and convection from the furnace gas to charge and the radiation from the furnace gas to the inner refractory wall surface and to the charge. The validity of the mathematical model was verified by the field measurements. The agreement between the measurement data and the numerical prediction is quite well. Honner et al. [6] conducted the measuring technique and developed computer model. Steel billets with the square crosssection of $100 \times 100 \mathrm{~mm}^{2}$ and length of $3.5 \mathrm{~m}$ were examined. Billets moved on water-cooled shore. The temperature difference is about $100 \mathrm{~K}$. Jaklic et al. [7] presented online simulation model of the steel-slab reheating process in a pusher-type. The heat exchange between the furnace gas, furnace wall and slab's surface was included whereas the heat conduction in the slab was calculated using the $3 \mathrm{D}$ finite difference method. The results showed that the thermal radiation was the main heat-transfer mechanism, and the geometry of the furnace enclosure was an important role in the heat transfer. Kim [8] studied a heat transfer model to predict the heat flux on the slab surface and temperature distribution in the slab by analysis the thermal radiation. Radiative heat flux was calculated from the radiative heat exchange within the furnace model using the finite volume method by considering the effect of furnace wall, slab, and combustion gas.

This study emphasizes on the temperature distribution of a billet in a reheating furnace. The objective is to investigate the temperature distribution subjected to thermal radiation of the enclosure surfaces in the reheating furnace comparing with the measurement data. The 2-D heat conduction is employed to predict the temperature distribution in a billet by using the finite volume method. The effect of the insulation thickness, flame temperature and furnace floor temperature on the temperature profile is investigated.

\section{Problem Formulation}

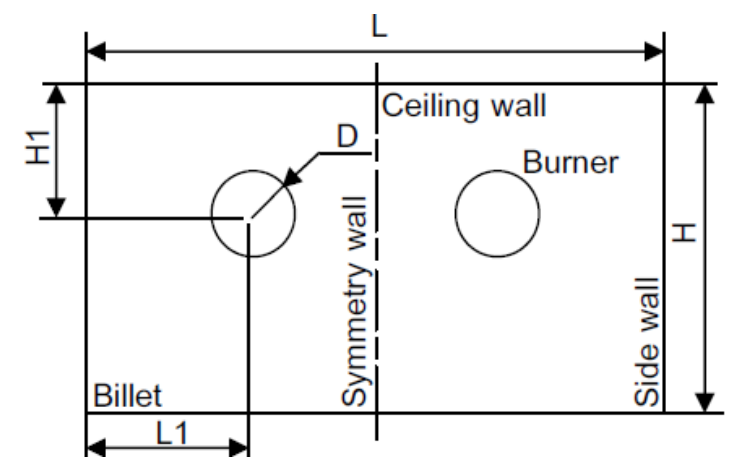

Fig. 1. The geometry of a reheating furnace. 
This study focuses on a billet located at the soaking zone before being pushed to the rolling process. The geometry and dimension of a reheating furnace is shown and presented in Fig. 1 and Table. 1. The rectangular enclosure of the reheating furnace is composed of the burners, side wall and ceiling wall. The combustion flame, which is generated by combustion process from the burner, is assumed to be a long cylinder.

Table 1. Dimension of a reheating furnace.

\begin{tabular}{lc}
\hline Surface & Area per unit depth $(\mathrm{m})$ \\
\hline Combustion flame & $360 \pi$ (perimeter) \\
Side wall (H) & 1.474 \\
Ceiling wall (L) & 2.6 \\
Symmetry wall (H) & 1.474 \\
L1 & 0.75 \\
H1 & 0.578 \\
\hline
\end{tabular}

Due to the symmetric geometry, therefore, a half of furnace is considered in this study. As a result, the five surfaces compose of the combustion flame, side wall, ceiling wall, symmetry wall and billet surfaces as depicted in Fig. 2.

Fig. 2. Symmetry geometry of this study.

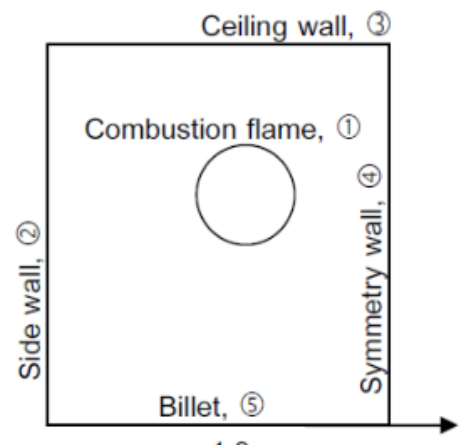

$x=1.3 \mathrm{~m}$

The billet is subjected to different heat fluxes as shown in Fig. 3. The dimensions of billet are the length of $2.6 \mathrm{~m}$ and the cross-sectional area (width $\times$ height) of $0.1 \times 0.1 \mathrm{~m}^{2}$.

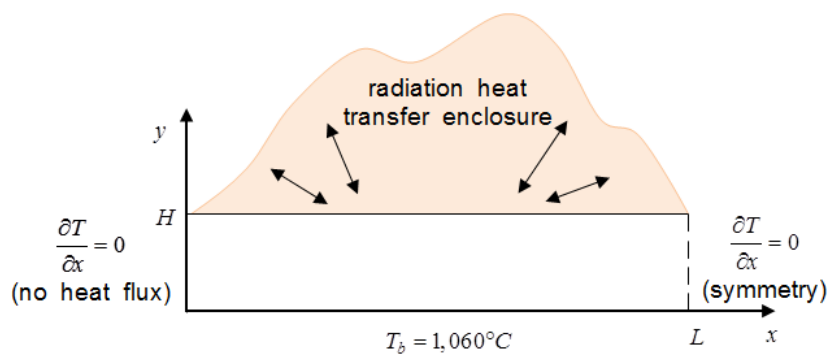

Fig. 3. Billet subjected to different heat fluxes.

For formulating the mathematic model, the assumptions are made as follows: (i) the system is considered under a steady state (ii) the problem is assumed two dimensional (iii) the problem is considered axis symmetric (iv) the surface of furnace wall and billet is assumed gray (v) the thermal properties of the billet and all surfaces are constant. According to above assumptions, the 2-D steady state heat conduction equation and the associated boundary condition can be expressed as

$$
\begin{gathered}
\frac{\partial}{\partial x}\left(k \frac{\partial T}{\partial x}\right)+\frac{\partial}{\partial y}\left(k \frac{\partial T}{\partial y}\right)=0 \\
x=0 \quad ; \quad \frac{\partial T}{\partial x}=0
\end{gathered}
$$




$$
\begin{array}{lll}
x=L / 2 & ; & \frac{\partial T}{\partial x}=0 \\
y=0 & ; & T=T_{f} \\
y=H & ; & k \frac{\partial T}{\partial y}=q_{\text {rad, enclosure }}^{\prime \prime}
\end{array}
$$

Due to the small the cross-sectional area of billet relative to the lateral one ; therefore, no heat flux at $x=0$ is expressed in the boundary condition as Eq. (2). The symmetry at the half length of the billet is shown in Eq. (3). The constant surface temperature on the furnace floor $\left(T_{f}\right)$ of $1,060^{\circ} \mathrm{C}$ is expressed in the boundary condition as Eq. (4). The main heat transfer mechanism is dominated by the thermal radiation within the enclosure surfaces including 5 surfaces which are the combustion flame, side wall, ceiling wall, symmetry wall, and billet surface. The billet itself is made of low-carbon steel. Thus, the thermal conductivity of a billet $(k)$ is a constant of $30 \mathrm{~W} / \mathrm{m}-\mathrm{K}$. In the furnace, the thermal radiation plays an important role for the heat transfer mechanism, leading to the negligible effect of the convection [9-12]. Since the radiation leaving a surface consists of emitted and reflected parts. Therefore, the total radiation energy leaving a surface is the radiosity $(J)[13,14]$,which can be expressed as

$$
\sigma T_{i}^{4}=J_{i}+\frac{1-\varepsilon_{i}}{\varepsilon_{i}} \sum_{j=1}^{N} A_{i} F_{i \rightarrow j}\left(J_{i}-J_{j}\right)
$$

The net rate of the radiation heat transfer of each surface $(Q)$ is written as

$$
\dot{Q}_{i}=\sum_{j=1}^{N} A_{i} F_{i \rightarrow j}\left(J_{i}-J_{j}\right)
$$

In the above two equations, the subscript "i" represents the surface of our interest whereas the subscript "i”" represents all surfaces. $\varepsilon$ is the emissivity of the surface, $F_{i \rightarrow j}$ is the view factor from the surface " $i$ " to the surface " $\mathrm{j}$ " and $A$ is the surface area. The view factor with the variation of element size is performed [15]. The temperature obtained from the field measurement and the emissivity [16] is shown in Table. 2. Since the hot gas temperature in the reheating furnace can be measured with the value of $1,250^{\circ} \mathrm{C}$. The flame temperature is normally higher than the hot gas temperature by approximately $100^{\circ} \mathrm{C}[17]$. The emissivity of the combustion flame is also assumed to be a black body surface with the emissivity of unity. Table 2 shows that the temperature of symmetry wall is an unknown because the heat flux is zero.

Table 2. Temperature and the emissivity obtained from the field measurement.

\begin{tabular}{lcc}
\hline Surface & Temperature $\left({ }^{\circ} \mathbf{C}\right)$ & Emissivity \\
\hline Combustion flame & 1,350 & 1 \\
Side wall & 1,150 & 0.8 \\
Ceiling wall & 1,150 & 0.8 \\
Symmetry wall & unknown & - \\
Billet & unknown & 0.9 \\
\hline
\end{tabular}

The heat loss of the furnace wall is an important criterion to consider [18]. Therefore, this study will consider the thickness of the furnace wall including three insulation layers with the different values of the thermal conductivity [19]. The insulation thickness is varied from $0,4,10,20,40$ to $50 \mathrm{~cm}$. The total heat transfer through the wall consists of the thermal conduction through three different wall layers and the convection heat transfer and the radiation heat transfer at the outer surface to the environment as shown in Fig. 4. The inner and outer furnace wall temperatures are unknown. Therefore, all the heat flux have to be converged the same value by using numerical method. The surrounding temperature is fixed at $30^{\circ} \mathrm{C}$ and the convection heat transfer coefficient of the surrounding of side wall $\left(b_{\text {conn,side }}\right)$ and ceiling wall $\left(h_{\text {conn, ceiling }}\right)$ is 5.42 and $6.84 \mathrm{~W} / \mathrm{m}^{2}-\mathrm{K}$, respectively. To simplify the non-linearity of the radiation heat transfer, this equation uses to the radiative heat transfer coefficient of side wall $\left(h_{\text {rad,side }}\right)$ and ceiling wall $\left(h_{\text {rad,ceiling }}\right)$ of 8.45 and $8.21 \mathrm{~W} / \mathrm{m}^{2}-\mathrm{K}$, respectively. 


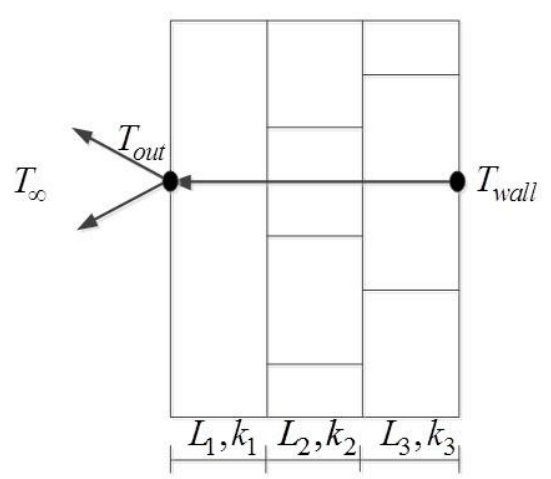

Fig. 4. Convection heat transfer and the radiation heat transfer to the environment.

\section{Numerical procedure}

The numerical procedure in this study consists of 2 parts: First, the calculation of the net thermal radiation within an enclosure, served as the boundary condition at the billet upper surface, is performed. The net thermal radiation in enclosure surfaces is determined by Gauss-elimination method. Second, the calculation of the temperature distribution of billet, which is governed by Eq. (1), is solved numerically by the finite volume method [20]. The temperature distribution is determined by Gauss-Seidel method [21]. A schematic diagram of grid arrangement is depicted in Fig. 5.

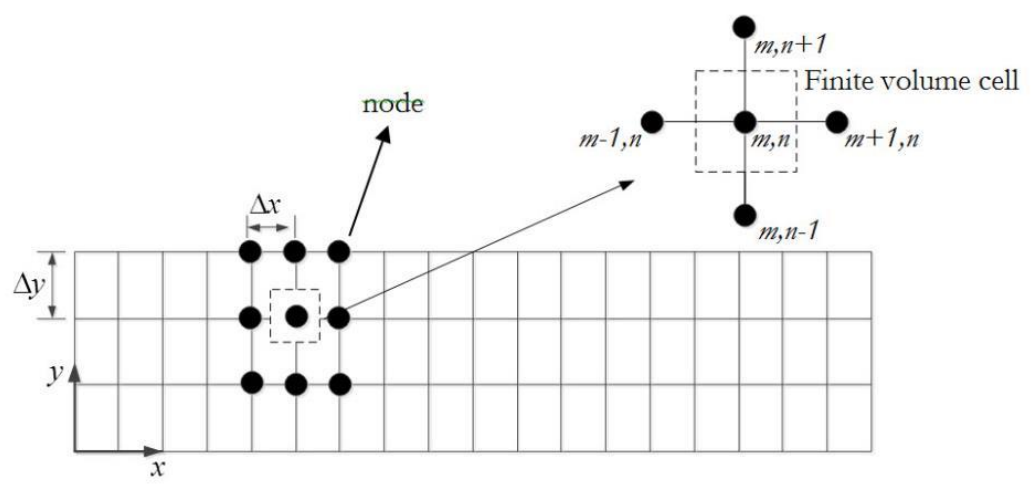

Fig. 5. A schematic diagram of grid arrangement.

The heat balance on each finite volume cell is performed by a discretization technique. The finite volume approximation of the interior node is expressed as shown in Eq. (8).

$$
(k \Delta y) \frac{\left(T_{m-1, n}-T_{m, n}\right)}{\Delta x}+(k \Delta x) \frac{\left(T_{m, n+1}-T_{m, n}\right)}{\Delta y}+(k \Delta y) \frac{\left(T_{m+1, n}-T_{m, n}\right)}{\Delta x}+(k \Delta x) \frac{\left(T_{m, n-1}-T_{m, n}\right)}{\Delta y}=0
$$

This expression can be rearranged into the Guess-Seidel format as follows:

$$
T_{m, n}=\frac{1}{(2 \Delta y / \Delta x)+(2 \Delta x / \Delta y)}\left[\frac{\Delta y}{\Delta x} T_{m-1, n}+\frac{\Delta y}{\Delta x} T_{m+1, n}+\frac{\Delta x}{\Delta y} T_{m, n-1}+\frac{\Delta x}{\Delta y} T_{m, n+1}\right]
$$

For the nodes at the billed edge and the billet corner, the finite volume approximation can be formulated in the similar manner with the corresponding boundary condition of that edge. To achieve the convergence criterion, the tolerance of the maximum absolute error of $10^{-10}$ is set. Grid independence is examined with the different values of $\Delta x$ and $\Delta y$. In this study, the grid sizes of $\Delta x$ and $\Delta y$, which are $0.026 \mathrm{~m}$ and $0.01 \mathrm{~m}$, is chosen corresponding to the $51 \times 11$ nodes in $x$ and $y$ direction, respectively. By comparing the selected grid sizes with the minimum ones, the max relative errors of the temperature profile in the billet is $0.019 \%$. 


\section{Results and discussion}

The numerical result is verified with the field measurement obtained by a thermal imaging camera located at the furnace exit. After the billet is discharged from the furnace, the thermal images with a resolution of $384 \times 288$ pixels are captured immediately [16]. The surface temperature of the billet measured by the camera has an uncertainty of $\pm 2 \%$. The temperature distribution between the numerical analysis and the field measurement is compared as shown in Fig. 6 . In this figure, the comparisons are made at the vertical location of $y=0,2,5,8$ and $10 \mathrm{~cm}$. The different symbolic marks represent the temperature distribution obtained from the field measurement. On the other hand, the different types of lines represent the temperature distribution obtained from the numerical prediction. Figure 7 illustrates the temperature contour in a billet. It can be seen that the numerical result and the field data are in a qualitative agreement. The filed data shows the temperature fluctuation especially at the upper surface of the billet because the hot spot originates from the position of the combustion flame, which provides the non-uniform heat flux to the upper surface of billet. In the numerical result, the maximum temperature and the average temperature of upper surface are $1,173^{\circ} \mathrm{C}$ and $1,167^{\circ} \mathrm{C}$, respectively. The average temperature at center is $1,114^{\circ} \mathrm{C}$. The difference between maximum and minimum temperature at the upper surface is $19.12^{\circ} \mathrm{C}$. It is noticed that the magnitude of the temperature fluctuation is lower when $y$ is decreased further away from the upper surface because of setting the temperature of the furnace floor of $1,060^{\circ} \mathrm{C}$. The maximum error occurs at $x$ $=0$ since the thermal image is captured while the billet is discharged from the furnace to the rolling process.

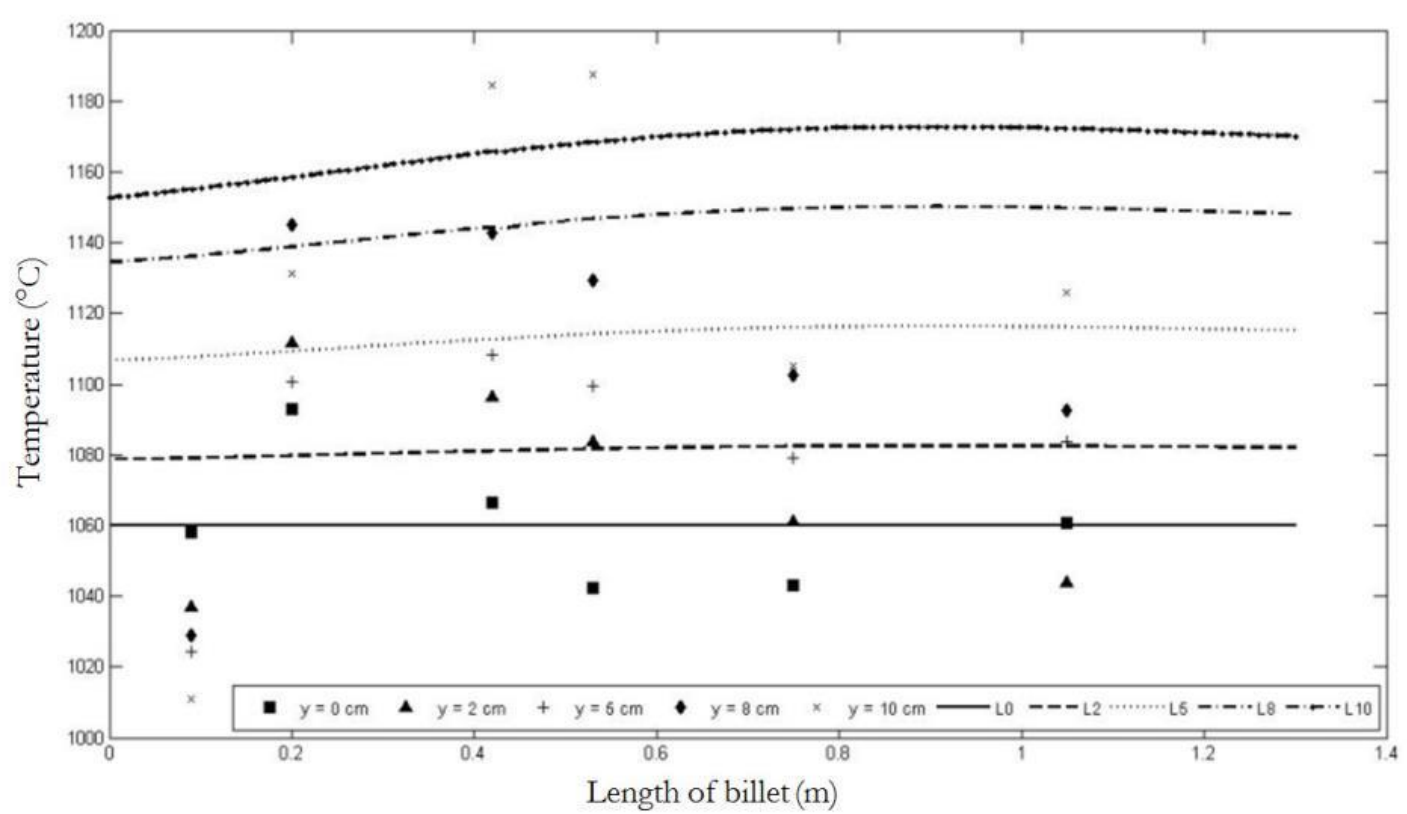

Fig. 6. Temperature distributions obtained from the numerical prediction and the field measurement.

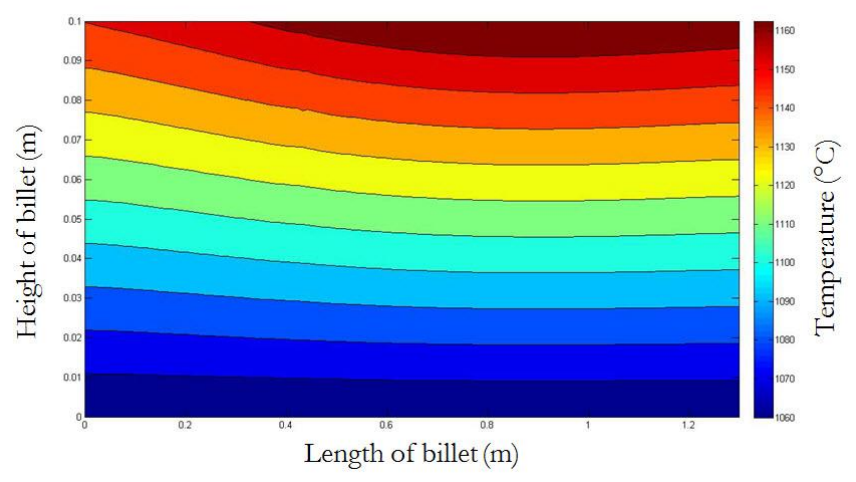

Fig. 7. Temperature contour in a billet. 
The heat balance diagram of the furnace enclosure in case of no insulation is depicted in Fig. 8 . The heat loss of the furnace floor, side wall and ceiling wall is $26.5 \%, 37.04 \%$ and $36.46 \%$, respectively, relative to the input heat from the net thermal radiation of $100 \%$. Thus, the majority of the heat losses is that through the side and ceiling walls at almost the same proportion.

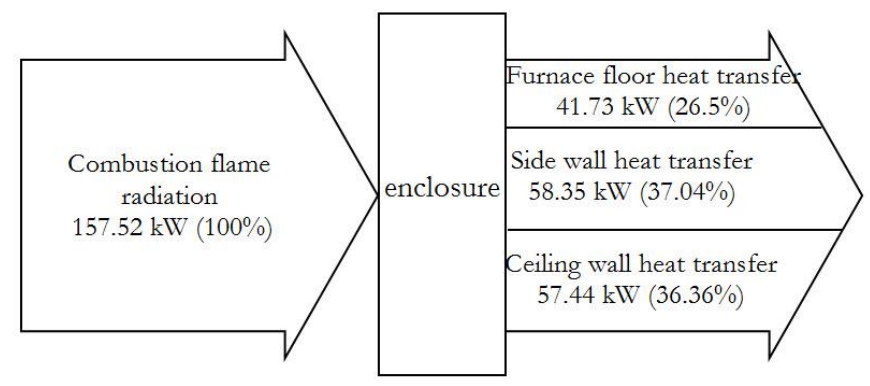

Fig. 8. Heat balance diagram of the billet.

To present the degree of the temperature uniformity of the billet, the standard deviation of the entire billet is presented. Figure 9 depicts the variation of the standard deviation with different insulation thicknesses. It is showed that as the insulation thickness increases from 0 to $40 \mathrm{~cm}$, the standard deviation is increased from $34.1^{\circ} \mathrm{C}$ to $54.6^{\circ} \mathrm{C}$ leading to the lower degree of the temperature uniformity. This is due to the fact that the higher the input heat to the billet, the higher the upper surface temperature of the billet relative to the fixed temperature at the bottom. Figure 10 depicts the variation of the temperature of the furnace wall and the billet with different insulation thicknesses. In case of $40-\mathrm{cm}$ insulation thickness, the temperature of the ceiling wall and the average temperature at the upper surface of the billet is $1,293^{\circ} \mathrm{C}$ and $1,232^{\circ} \mathrm{C}$ comparing to those of $1,150^{\circ} \mathrm{C}$ and $1,167^{\circ} \mathrm{C}$ in case of no insulation. It should be noted that the asymptotic behavior of the temperature of the furnace wall and the billet is observed when the insulation thickness is increased to a certain level. Figure 11 depicts the variation of heat transfer rates with different insulation thicknesses. By comparing the insulation thickness of $40 \mathrm{~cm}$ with no insulation, the heat loss through combined furnace wall decreases from $115.79 \mathrm{~kW}$ to $3.29 \mathrm{~kW}$ corresponding to the reduction of $97.16 \%$. The radiative heat transfer rate from the combustion flame also decreases from $157.52 \mathrm{~kW}$ to $70.51 \mathrm{~kW}$ corresponding to the reduction of $55.24 \%$. However, the heat loss from furnace floor increases from $41.73 \mathrm{~kW}$ to $67.36 \mathrm{~kW}$ corresponding to the increase of $61.42 \%$ due to the proportionality between the input heat to the billet and the heat loss from the furnace floor.

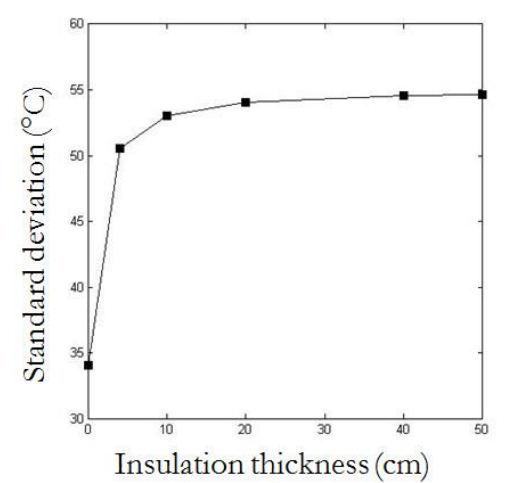

Fig. 9. Standard deviation with different insulation thicknesses. 


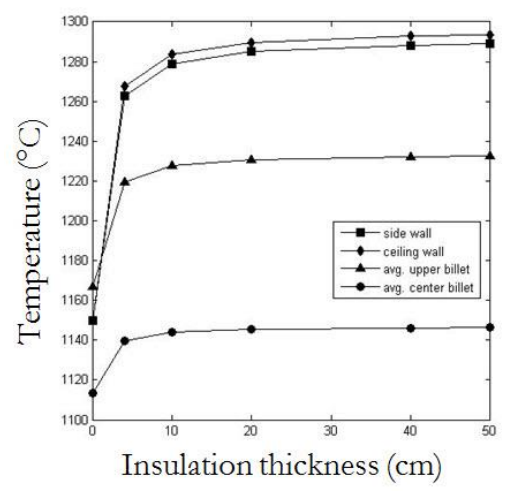

Fig. 10. Variation of temperature of furnace wall and billet with different insulation thicknesses.

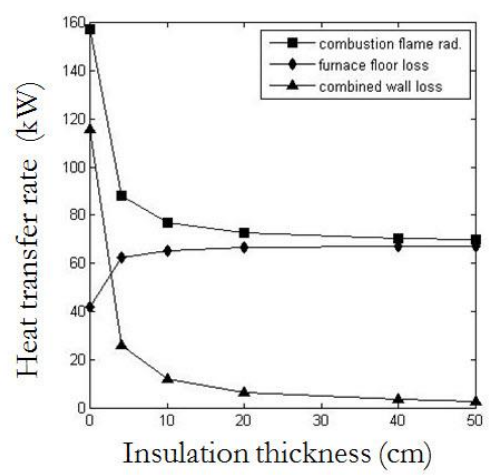

Fig. 11. Variation of heat transfer with different insulation thicknesses.

The standard deviation with different flame temperatures is shown in Fig. 12. It is showed that when the flame temperature is higher, the standard deviation is also higher causing the reduction of the degree of the temperature uniformity. As the flame temperature increases from $1,250^{\circ} \mathrm{C}$ to $1,450^{\circ} \mathrm{C}$, the standard deviation is increased from $33.1^{\circ} \mathrm{C}$ to $78.3^{\circ} \mathrm{C}$. The degree of the temperature uniformity is decreased because the higher the flame temperature, the higher the input heat to the billet resulting in the more fluctuated the billet temperature. Figure 13 depicts the variation of the temperature of furnace wall and billet with different flame temperatures. When the flame temperature is $1,250^{\circ} \mathrm{C}$, the temperature of the ceiling wall and the average temperature of the upper surface of the billet is $1207^{\circ} \mathrm{C}$ and $1165^{\circ} \mathrm{C}$, respectively, comparing with those of $1,382^{\circ} \mathrm{C}$ and $1,308^{\circ} \mathrm{C}$ at the flame temperature of $1,450^{\circ} \mathrm{C}$. The linear relation between those temperatures and the flame temperature from 1,200 to $1,400^{\circ} \mathrm{C}$ is observed. Figure 14 depicts the variation of heat transfer rate with different flame temperature. As the flame temperature decreases from $1,350^{\circ} \mathrm{C}$ to $1,250^{\circ} \mathrm{C}$, the radiative heat transfer rate from the combustion flame is decreased from $70.51 \mathrm{~kW}$ to $43.87 \mathrm{~kW}$ corresponding to the reduction of $37.78 \%$ whereas the heat loss through the furnace floor decreases from 67.22 to $40.81 \mathrm{~kW}$ corresponding to the reduction of $39.29 \%$. In contrast, As the flame temperature increases from $1,350^{\circ} \mathrm{C}$ to $1,450^{\circ} \mathrm{C}$, the radiative heat transfer rate from the combustion flame increases from $70.51 \mathrm{~kW}$ to $100.12 \mathrm{~kW}$ corresponding to the increase of $41.99 \%$ whereas the heat loss through the furnace floor increases from 67.22 to $96.51 \mathrm{~kW}$ corresponding to the increase of $43.57 \%$. When the flame temperature increases, the higher the temperature difference between the flame and the floor, the higher the heat input to the billet and the higher the heat output from the billet as well. It is noted that the relationship between both heat losses and the flame temperature is almost linear. 


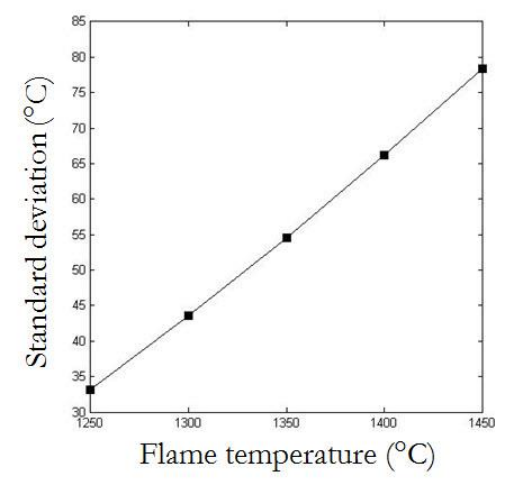

Fig. 12. Standard deviation with different flame temperatures.

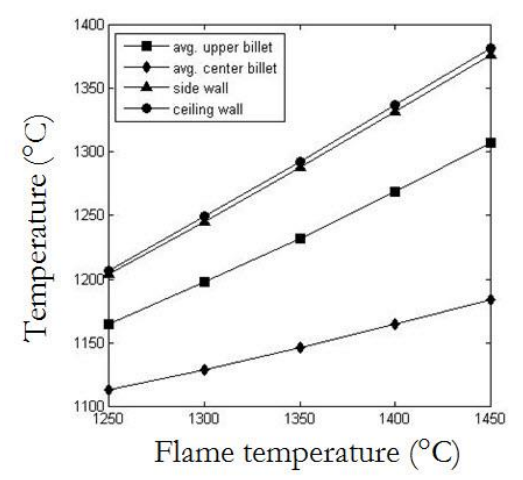

Fig. 13. Variation of the temperature of furnace wall and billet with different flame temperatures.

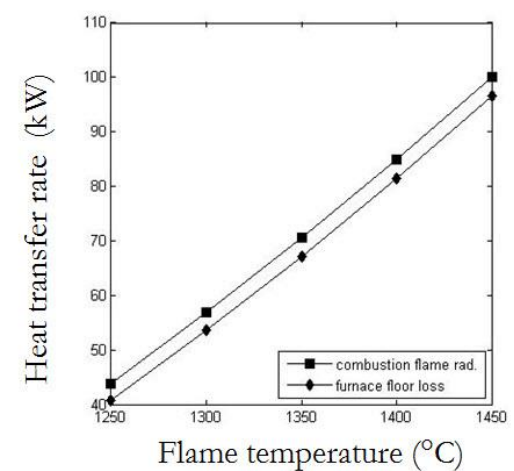

Fig. 14. Variation of heat transfer with different flame temperatures.

The standard deviation with different furnace floor temperatures is depicted in Fig. 15. It can be explained that when the furnace floor temperature increases from $1,040^{\circ} \mathrm{C}$ to $1,080^{\circ} \mathrm{C}$, the standard deviation is decreased from $58.2^{\circ} \mathrm{C}$ to $50.9^{\circ} \mathrm{C}$. This is due to the fact the floor temperature is increased relatively closed to the flame temperature causing the higher degree of the temperature uniformity of the billet. Figure 16 depicted the variation of the temperature of furnace wall and billet with different furnace floor temperature. When the floor temperature is $1,040^{\circ} \mathrm{C}$, the temperature of the ceiling wall and the average temperature of the upper surface of the billet is $1,289^{\circ} \mathrm{C}$ and $1,224^{\circ} \mathrm{C}$, respectively, comparing with those of $1,297^{\circ} \mathrm{C}$ and $1,241^{\circ} \mathrm{C}$ at the floor temperature of $1,080^{\circ} \mathrm{C}$. It is noticed that the average temperature of the upper surface of the billet is more sensitive to the floor temperature than the temperature at the furnace wall. The relation between those temperatures and the floor temperature is nearly linear. Figure 17 depicts the variation of heat transfer rate with different furnace floor temperature. It can be explained that the heat loss through the furnace floor decrease when the temperature of the furnace wall increase because the temperature difference between the floor and the flame as the thermal driving force decreases. It is showed that as the furnace floor temperature increases from $1,060^{\circ} \mathrm{C}$ to $1,080^{\circ} \mathrm{C}$, the radiative heat transfer rate from combustion flame decreases from $70.51 \mathrm{~kW}$ to $66.10 \mathrm{~kW}$ corresponding to 
the reduction of $6.33 \%$. Moreover, the heat loss through the furnace floor also decreases from $67.22 \mathrm{~kW}$ to $62.72 \mathrm{~kW}$ corresponding to the reduction of $6.69 \%$. On the other hand, as the furnace floor temperature decreases from $1,060^{\circ} \mathrm{C}$ to $1,040^{\circ} \mathrm{C}$, the radiative heat transfer rate from combustion flame increases from $70.51 \mathrm{~kW}$ to $75.00 \mathrm{~kW}$ corresponding to the increase of $6.37 \%$. The heat loss through the furnace floor also increases from $67.22 \mathrm{~kW}$ to $71.65 \mathrm{~kW}$ corresponding to the increase of $6.59 \%$. It is noted that the linear relationship between both heat losses and the floor temperature is observed.

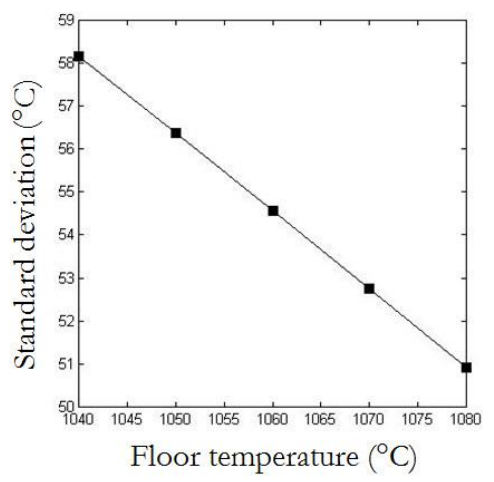

Fig. 15. Standard deviation with different furnace floor temperatures.

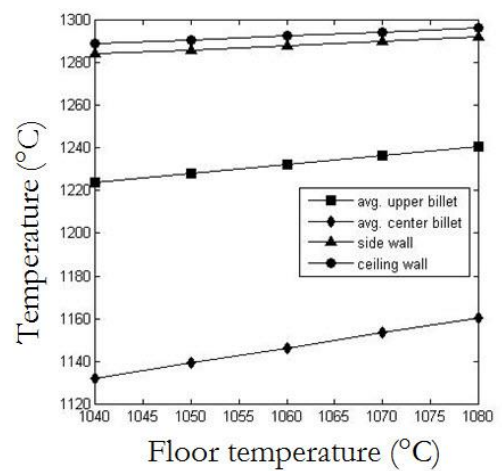

Fig. 16. Variation of the temperature of furnace wall and billet with different furnace floor temperatures.

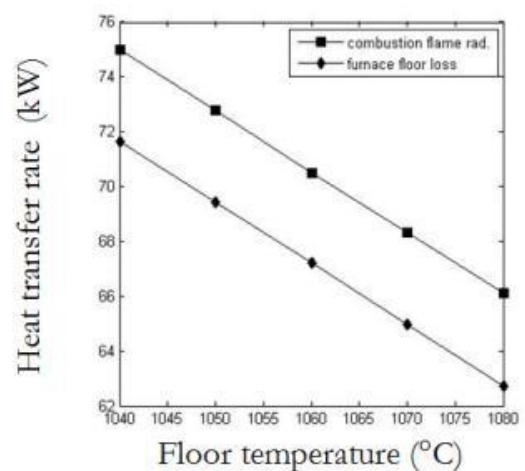

Fig. 17. Variation of heat transfer with different furnace floor temperatures.

\section{Conclusion}

An investigation of the temperature uniformity and the heat transfer characteristics of a billet in a reheating furnace have been presented in this study. The reheating furnace is considered as an enclosure with five surfaces consisting of the combustion flame, side wall, ceiling wall, symmetry wall, and billet upper surface. The 2-D steady state heat conduction equation of a billet subjected to different heat fluxes is proposed. The net thermal radiation in the enclosure is solved by the Gauss-elimination technique. The finite volume method with the Gauss-Seidel iterative technique is employed to solve the 2-D heat conduction equation. 
The comparison between the numerical result and the field measurement data leads to the qualitative agreement. It is indicated that the maximum temperature is located on the upper surface of the billet due to the position of the combustion flame. In this study, the improvement of the temperature uniformity of the billet is investigated by varying the insulation thickness, the combustion flame temperature and the furnace floor temperature. It is showed that the thinner insulation thickness, the lower combustion flame temperature and the higher furnace floor temperature leads to the higher degree of temperature uniformity of the billet.

\section{References}

[1] Bureau of Energy Efficiency, "Energy efficiency in thermal utilities," Ministry of Power, India, 2005.

[2] B. Lin, Y. Wu, and L. Zhang, "Estimates of the potential for energy conservation in the Chinese steel industry," Energy Policy, vol. 39, pp. 3680-3689, 2011.

[3] Y. Sakamoto, Y. Tonooka, and Y. Yanagisawa, "Estimation of energy consumption for each process in the Japanese steel industry: A process analysis," Energy Conversion \& Management, vol. 40, pp. 1129 1140, 1999

[4] D. Lindholm and B. Leden, "A finite element method for solution of the three-dimensional timedependent heat-conduction equation with application for heating of steels in reheating furnace," Numerical Heat Transfer, vol. 35, pp. 155-172, 1999.

[5] T. Kolenko, B. Glogovac, and T. Jaklic, "An analysis of a heat transfer model for situations involving gas and surface radiative heat transfer," Communications in Numerical Methods in Engineering, vol. 15, pp. 349-365, 1999.

[6] M. Honner, Z. Vesely, and M. Svantner, "Temperature and heat transfer measurement in continuous reheating furnaces," vol. 32, pp. 225-232, 2003.

[7] A. Jaklic, F. Vode, and T. Kolenko, "Online simulation model of the slab-reheating process in a pusher-type furnace," Applied Thermal Engineering, vol. 27, pp. 1105-1114, 2007.

[8] M. Y. Kim, "A heat transfer for the analysis of transient heating of the slab in a direct-fired walking beam type reheating furnace," International Journal of Heat and Mass Transfer, vol. 50, pp. 3740-3748, 2007.

[9] A. M. Maki, P. J. Osterman, and M. J. Luomala, "Numerical study of the pusher-type slab reheating furnace." Scandinavian Journal of Metallurgy, vol. 31, pp. 81-87, 2002.

[10] S. H. Han, D. Chang, and C. Y. Kim, "A numerical analysis of slab heating characteristics in a walking beam typereheating furnace," International Journal of Heat and Mass Transfer, vol. 53, pp. 3855-3861, 2010.

[11] J. H. Jang, D. E. Lee, M. Y. Kim, and H. G. Kim, "Investigation of the slab heating characteristics in a reheating furnace with the formation and growth of scale on the slab surface," International Journal of Heat and Mass Transfer, vol. 53, pp. 4326-4332, 2010.

[12] S. H. Han, D. Chang, and C. Huh, "Efficiency analysis of radiative slab heating in a walking-beamtype reheating furnace." Energy, vol. 36, pp. 1265-1272, 2011.

[13] F. P Incopera and D. P. Dewitt, "Radiation exchange between surfaces," in Fundamentals of Heat and Mass Transfer, $5^{\text {th }}$ ed. New York: John Wiley \& Sons, 2002, pp. 811-847.

[14] Y. A. Cengel, Heat and Mass Transfer: A Practical Approach. McGraw-Hill Education, 2006.

[15] T. Khoukit and C. Tangthieng, "Effect of the view factor in enclosure surface on the thermal radiation to a billet in a reheating furnace," in Proc. $5^{\text {th }}$ TSME International Conference on Mechanical Engineering, Chiang Mai, Thailand, 2014.

[16] E. Somriewwongkul, "A numerical study of the temperature distribution in a billet at the reheating furnace discharge doors taking the doors heat loss into account." M.S. thesis, Department of Mechanical Engineering, Faculty of Engineering, Chulalongkorn University, Bangkok, Thailand, 2011.

[17] W. Trinks, M. H. Mawhinney, R. A. Shannon, R. J. Reed, and J. R. Carvey, Industrial Furnaces, $6^{\text {th }}$ ed. New York: John Wiley\&Sons, 2004.

[18] B. Songrit, "Study on energy saving of furnace wall storage loss by using ceramic fiber," M.S. thesis, Department of Mechanical Engineering, Faculty of Engineering, Chulalongkorn University, Bangkok, Thailand, 2008. 
[19] TSS refractory company. Thermal Conductivity of Insulation Furnace Wall [Online]. Available http://www.tssrefractory.com

[20] S. V. Patankar, Numerical Heat Transfer and Fluid Flow. USA: Taylor\&Francis, 1980.

[21] H. K. Versteeg and W. Malalasekera, An Introduction to Computational fluid Dynamics the Finite Volume Method, 2nd ed. England: Pearson Education Limited, 2007. 